\title{
Minireviews
}

\section{Glycoconjugation as a Promising Treatment Strategy for Psoriasis}

\author{
Sebastian Makuch, Marta Woźniak, Monika Krawczyk, Gabriela Pastuch-Gawołek, \\ Wiesław Szeja, and Siddarth Agrawal
}

Department of Pathology, Faculty of Medicine, Wroclaw Medical University, Wroclaw, Poland (S.M., M.W., S.A.); Department and Clinic of Internal Medicine, Occupational Diseases, Hypertension and Clinical Oncology, Wroclaw Medical University, Wroclaw, Poland (S.A.); and Department of Organic Chemistry, Bioorganic Chemistry and Biotechnology, Faculty of Chemistry (M.K., G.P.-G., W.S.) and Biotechnology Centre (M.K., G.P.-G., W.S.), Silesian University of Technology, Gliwice, Poland

Received November 5, 2019; accepted February 10, 2020

\section{ABSTRACT}

Despite the progress in the development of novel treatment modalities, a significant portion of patients with psoriasis remains undertreated relative to the severity of their disease. Recent evidence points to targeting the glucose transporter 1 and sugar metabolism as a novel therapeutic strategy for the treatment of psoriasis and other hyperproliferative skin diseases. In this review, we discuss glycoconjugation, an approach that facilitates the pharmacokinetics of cytotoxic molecules and ensures their preferential influx through glucose transporters. We propose pathways of glycoconjugate synthesis to increase effectiveness, cellular selectivity, and tolerability of widely used antipsoriatic drugs. The presented approach exploiting the heightened glucose requirement of

\section{Introduction}

An increasing body of evidence is accumulating, suggesting a significant surge in the frequency of autoimmune diseases in the last decades (Lohi et al., 2007; Lerner and Matthias, 2015a). Psoriasis, rheumatoid arthritis, psoriatic arthritis, multiple sclerosis, inflammatory bowel diseases, and systemic lupus erythematosus are several examples (Lerner and Matthias, 2015a,b). All of the mentioned conditions are a consequence of chronic activation of $\mathrm{T}$ and $\mathrm{B}$ lymphocytes in the absence of an infection or other detectable cause (Davidson and Diamond, 2001). The overall prevalence of autoimmunity is approximately $3 \%-5 \%$ in the general population, but the effects on mortality and morbidity are significant (Jacobson et al., 1997; Eaton et al., 2007). Ironically, despite enormous advances in the molecular sciences, diagnostic methods, and clinical classification, there is still an

This work was supported by the National Center for Research and Development Grant [TANGO3/426098/NCBR/2019].

https://doi.org/10.1124/jpet.119.263657. proliferating keratinocytes bears the potential to revolutionize the management of psoriasis.

\section{SIGNIFICANCE STATEMENT}

Recent findings concerning the fundamental role of enhanced glucose metabolism and glucose transporter 1 overexpression in the pathogenesis of psoriasis brought to light approaches that proved successful in cancer treatment. Substantial advances in the emerging field of glycoconjugation highlight the rationale for the development of glucose-conjugated antipsoriatic drugs to increase their effectiveness, cellular selectivity, and tolerability. The presented approach offers a novel therapeutic strategy for the treatment of psoriasis and other hyperproliferative skin diseases. urgent need to improve the therapeutic outcome of patients with an autoimmune disease.

One of the most prevalent autoimmune diseases is psoriasis, which is a chronic inflammatory skin condition that affects $2 \%-3 \%$ of the population worldwide (Langley et al., 2005). Symptoms of psoriasis, which include redness, scaling, flaking, pruritus, skin tightness, pain, and bleeding, have a significant impact on patients' physical and mental well-being (Feldman et al., 2014). Patients with psoriatic diseases cannot only have skin and joint impairment but can also experience decreased quality of life and work productivity as well as severe medical comorbidities, such as increased cardiovascular events and depression (Armstrong et al., 2013; Lebwohl et al., 2014). The dominant feature of psoriasis is an aberrant hyperproliferation of keratinocytes (Lowes et al., 2007), which are the primary cell type of the epidermis and vital participants of the immune system, recruiting $\mathrm{T}$ cells to the skin (Lowes et al., 2014). Activated by interleukin (IL)-12 and IL23, IL-17-producing T cells (Gerosa et al., 2008) produce abundant key psoriatic cytokines, such as tumor necrosis factor (TNF- $\alpha$ ), interferon-gamma, and IL-17 and IL-23, that 
mediate effects on keratinocytes to intensify skin inflammation (Kim and Krueger, 2015). Exaggerated proliferation of keratinocytes is a hallmark of psoriasis and results from overexpression of the previously mentioned cytokines and growth factors (Hiebert and Werner, 2018). Currently used treatment agents, such as calcineurin inhibitors, anti-interleukin monoclonal antibodies against proinflammatory cytokines, fumaric acid esters, glucocorticoids, retinoids, and vitamin $\mathrm{D}$ derivatives, tend to suppress chronic inflammation (Boehncke and Schön, 2015). Unfortunately, despite the progress in the development of novel treatment modalities over the past decades, studies reveal that a significant proportion of patients with psoriasis remain undertreated relative to the severity of their disease (Lebwohl et al., 2014). Patients experience treatment failure with, or intolerance to, traditional systemic therapies and/or phototherapy and switch to biologic agents as second-line therapy. Side effects are the main reason for discontinuing traditional systemic therapies, whereas lack of efficacy is the main reason for discontinuing biologic agents (Lambert et al., 2017). Biologics were reported to lose their effectiveness after long-term use (Levin et al., 2014). The toxicity of traditional compounds such as methotrexate prevents many patients from obtaining a favorable outcome from the treatment because of the development of multiple toxic effects, including bone marrow suppression and gastrointestinal ulceration (Roenigk et al., 1988; Pearce and Wilson, 1996). Only $36 \%-58 \%$ of patients with moderate to severe psoriasis treated according to the guidelines reach current therapeutic targets of PASI75 (Psoriasis Area and Severity Index - represents the percentage of patients who have achieved a $75 \%$ or more reduction of the score and PASI90 (Psoriasis Area and Severity Index - represents the percentage of patients who have achieved a $90 \%$ or more reduction of the score) at 1 year, highlighting a gap in efficacy between selective clinical trials and the real-world setting. A population-based survey of patients, dermatologists, and rheumatologists found a high treatment dissatisfaction among the patients and a need for safe, effective, and easy-to-use therapies for psoriasis (Lebwohl et al., 2016). Thus, new, rationally designed agents are needed to replace or complement currently applied therapies. Glycoconjugation is a strategy that offers improved water solubility and stability and the potential for a selective accumulation of conjugated drugs by targeting glucose transporter 1 (GLUT1) receptors (Fig. 1), whose expression is highly abundant in proliferating psoriatic keratinocytes (Crunkhorn, 2018). A recently published paper by Zhang et al. (2018) in Nature Medicine revealed that glucose metabolism is essential for proliferating keratinocytes, highlighting a potential therapeutic target for pathologic hyperproliferation. In this review, we propose the conjugation of glucose to antipsoriatic drugs as a novel strategy for targeted delivery through GLUT1 receptors, which may potentially increase the effectiveness, cellular selectivity, and tolerability of antipsoriatic drugs and, thus, revolutionize the management of psoriasis.

\section{Current Treatment Options and Their Limitations}

The choice of psoriasis treatment depends on a wide variety of factors, such as disease severity, its effects on the patient's life, comorbidities, and health care access. Psoriatic patients are often assigned into two groups: those with mild psoriasis and those with moderate to severe psoriasis (Mrowietz et al., 2011). Mild psoriasis affects less than $3 \%$ of body surface area and responds well to topical application of vitamin D analogs or corticosteroids as well as localized UVB phototherapy (O'Neill and Feldman, 2010). Combinations of potent topical corticosteroids and vitamin $\mathrm{D}$ analogs or UVB phototherapy are commonly prescribed by dermatologists. With proper adherence, considerable improvement with these therapies may be seen in as little as 1 week, although several weeks may be required for full benefits (Kleyn et al., 2019). However, treatments including vitamin D analogs as well as UVB phototherapy may cause undesirable side effects, such as mild irritant dermatitis, hypercalcemia, burning, or photoaging (Singh et al., 2016; Kim et al., 2017). On the other hand, moderate to severe psoriasis is defined as involvement of more than $3 \%-10 \%$ of the body surface area and usually requires the addition of systemic treatments in combination with topical therapy. The effectiveness of topical therapy alone is limited in cases with severe symptoms, extensive skin lesions, and poor quality of life. Additionally, long-term use of topical corticosteroids induces side effects of local skin ulceration or suppression of the hypothalamic-pituitary-adrenal axis (Castela et al., 2012). Notably, methotrexate continues to be used as a first-line systemic agent since 1971 despite the fact that it yields an improvement in only $20 \%-30 \%$ of all patients with moderate-to-severe psoriasis (Maybury et al., 2014). Toxicity prevents many patients from obtaining a favorable outcome from the drug. It has been reported that multiple toxic effects occur in two-thirds of patients, and up to roughly $30 \%$ of patients discontinue methotrexate therapy within the first year of treatment because of hepatotoxicity (Bookstaver et al., 2008; Conway et al., 2015). New biologic and small-molecule therapies have been developed to complement or replace traditional drugs (Table 1). Biologic molecules that are being currently used for the treatment of psoriasis have been thoroughly described in several reviews (Lowes et al., 2007; Rønholt and Iversen, 2017; Rendon and Schäkel, 2019). Unlike earlier psoriatic treatments, biologic agents were designed to target $\mathrm{T}$ cells and specific inflammatory mediators, such as TNF or IL. The major concern of biologic therapeutics is the impact of longterm chronic immunosuppression, which may potentially lead to increased infection and cancer risk (Lowes et al., 2007). Only conclusions obtained from long-term clinical studies are able to distinguish whether the new therapies are successful. Biologics are also costly, inaccessible for the general public, and require repeated injections. Thus, the development of novel drugs to increase effectiveness and reduce toxicity is desirable.

Zhang et al. (2018) have recently found that targeting the glucose transporter GLUT1 and sugar metabolism offers a novel therapeutic strategy for the treatment of psoriasis and other hyperproliferative skin diseases. According to their results, excessively proliferating keratinocytes require glucose uptake through GLUT1, which is not a requisite for healthy skin development and function. The findings indicate that targeting elevated glucose intake and GLUT1 overexpression, which provide clinically corroborated strategies for cancer treatment (Bronstein et al., 2011; Vander Heiden, 2011; Cantor and Sabatini, 2012), could lead to the 
development of safe and effective therapies for skin diseases (Fig. 1).

\section{Glycoconjugation for Selective Glucose Transporter Targeting}

Glucose is a fundamental energy source that is absorbed by cells through the plasma membrane. The transporters that allow cellular uptake of glucose can be classified into two distinct families: 1) active and energy-dependent sodium/ glucose cotransporters and 2) passive, facilitative transporters (GLUTs) that use electrochemical gradients to transport glucose. There are 14 mammalian facilitative glucose transporters, among which GLUT1, the most common glucose transporter, is widely overexpressed in many human cancers, including hepatic, pancreatic, breast, esophageal, brain, renal, lung, cutaneous, colorectal, endometrial, ovarian, and cervical (Calvo et al., 2010; Szablewski, 2013; Liu and Auguste, 2015). To maintain cellular homeostasis, growth, and proliferation, cancer cells significantly increase glucose uptake and the flux of metabolites through glycolysis. This phenomenon, termed "the Warburg effect," arises from mitochondrial metabolic changes and is a characteristic trait of cancer (Warburg, 1956). Elevated glucose uptake and GLUT overexpression are frequent in neoplasms and provide clinically corroborated strategies for cancer treatment (Bronstein et al., 2011; Vander Heiden, 2011; Cantor and Sabatini, 2012). In general, glycoconjugation offers improved water solubility and stability and the potential for selective targeting. Therefore, it becomes an appealing strategy for targeted delivery of clinically prescribed drugs (Medina and Owen, 2002; Calvaresi and Hergenrother, 2013; Srinivasarao et al., 2015; Ashley, 2016), with significant advances in the field, reaching as far as late-stage human clinical trials (Pohl et al., 1995; Medina and Owen, 2002; Calvaresi and Hergenrother, 2013; Liu and Auguste, 2015; Granchi et al., 2016; Patra et al., 2016; Srinivasarao and Low, 2017).

Historically, it was suggested that the heightened requirement for glucose, constitutive overexpression of GLUT1 and the persistent metabolism of glucose to lactate, is an adaptation to a stressful and dynamic microenvironment, which is characteristic exclusively for solid tumors, in which concentrations of crucial nutrients and oxygen are spatially and

\section{A}

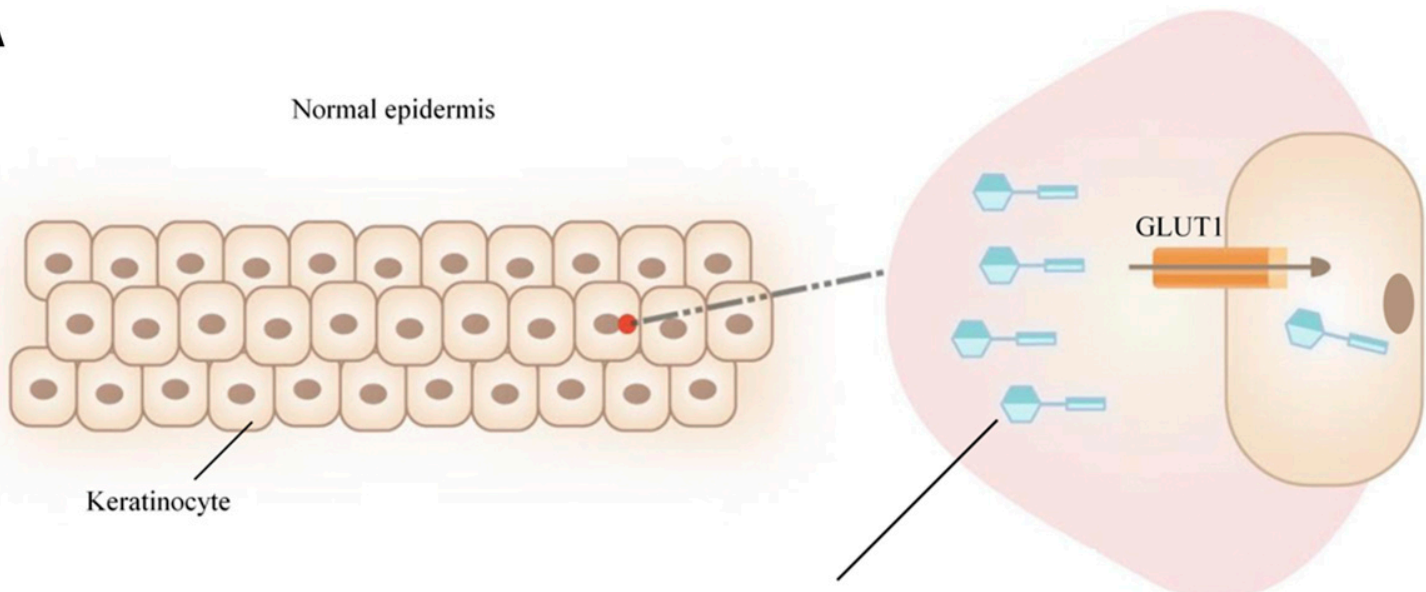

Glucose-conjugated antipsoriatic drugs

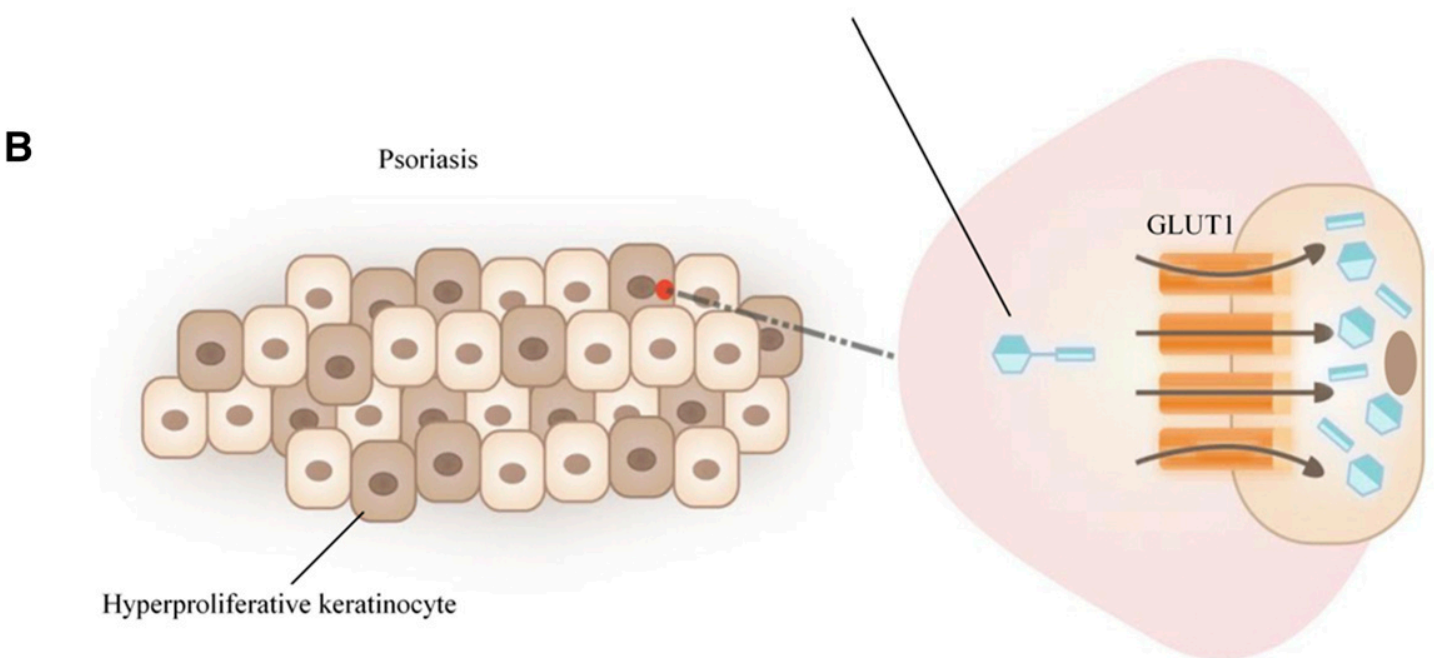

Fig. 1. Transport of glucose-conjugated antipsoriatic drugs through GLUT1 in keratinocytes. In contradistinction to healthy keratinocytes (A), hyperproliferative keratinocytes are composed of overexpressed GLUT1 transporters, which contribute to significantly higher uptake of glucoseconjugated drugs (B). As a result, in chronic inflammation, the glucose-conjugated antipsoriatic drugs may lead to reduced inflammation and hyperproliferation of keratinocytes. The intracellular cleavage of acid-labile linkers in the more acidic environment results in controlled drug release in hyperproliferative keratinocytes. 
TABLE 1

FDA-approved traditional and biologic therapies for psoriasis

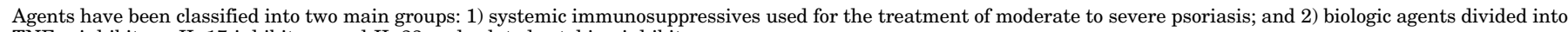
TNF- $\alpha$ inhibitors, IL-17 inhibitors, and IL-23 and related cytokine inhibitors.

\begin{tabular}{|c|c|c|}
\hline Class & Compound & Mechanism of action \\
\hline \multirow{6}{*}{$\begin{array}{l}\text { Traditional agents commonly used in } \\
\text { treatment of moderate to severe } \\
\text { psoriasis }\end{array}$} & Methotrexate & $\begin{array}{l}\text { A folate antimetabolite that inhibits T-cell activation as well as DNA synthesis and } \\
\text { repair (Chan and Cronstein, 2013) }\end{array}$ \\
\hline & Cyclosporine & $\begin{array}{l}\text { A calcineurin inhibitor that leads to reduced production of interleukin-2 (Matsuda } \\
\text { and Koyasu, 2000) }\end{array}$ \\
\hline & Apremilast & $\begin{array}{l}\text { A phosphodiesterase } 4 \text { inhibitor that leads to increased intracellular cAMP levels } \\
\text { to regulate various inflammatory mediators (e.g., decreases levels of TNF- } \alpha \text { and } \\
\text { interleukin-23, increases level of interleukin-10) (Schafer, 2012) }\end{array}$ \\
\hline & Tofacitinib & $\begin{array}{l}\text { An inhibitor of interleukin-2-induced phosphorylation of JAK3 and STAT5, which } \\
\text { are involved in immune cell function (Hodge et al., 2016) }\end{array}$ \\
\hline & $\begin{array}{l}\text { Fumaric acid } \\
\text { esters }\end{array}$ & $\begin{array}{l}\text { Fumarate derivatives that activate Nrf2 to inhibit the production of } \\
\text { proinflammatory cytokines, such as IL-12 and IL-23 (Balak, 2015) }\end{array}$ \\
\hline & Acitretin & $\begin{array}{l}\text { A retinoid that binds to and activates retinoid receptors to normalize keratinocyte } \\
\text { differentiation in the epidermis (Tippmann et al.,2009) }\end{array}$ \\
\hline TNF- $\alpha$ inhibitors & Etanercept & $\begin{array}{l}\text { A recombinant protein that binds to the Fc portion of IgG and blocks soluble TNF- } \alpha \\
\text { interaction with receptors on the cell surface (Goffe and Cather, 2003) }\end{array}$ \\
\hline & Infliximab & $\begin{array}{l}\text { A chimeric monoclonal antibody that interferes with endogenous TNF- } \alpha \text { (Guo et al., } \\
\text { 2013) }\end{array}$ \\
\hline & Adalimumab & A recombinant monoclonal antibody against TNF- $\alpha$ (Mease, 2007) \\
\hline & $\begin{array}{l}\text { Certolizumab } \\
\text { pegol }\end{array}$ & $\begin{array}{l}\text { A pegylated Fab' fragment of humanized monoclonal antibody against TNF- } \alpha \text {; } \\
\text { selectively binds and neutralizes the activity of human TNF- } \alpha \text { (Acosta-Felquer } \\
\text { et al., 2016) }\end{array}$ \\
\hline Interleukin 17 inhibitors & Secukinumab & $\begin{array}{l}\text { A human IgG1 } \kappa \text { monoclonal antibody that selectively binds to interleukin-17A and } \\
\text { inhibits the interaction of this cytokine with the IL-17 receptor (Fala, 2016) }\end{array}$ \\
\hline & Ixekizumab & $\begin{array}{l}\text { A humanized IgG4 } \kappa \text { monoclonal antibody against IL-17A, that inhibits the release } \\
\text { of proinflammatory cytokines and chemokines (Monin and Gaffen, 2018) }\end{array}$ \\
\hline & Brodalumab & $\begin{array}{l}\text { A human monoclonal IgG2 antibody that acts as an antagonist of IL-17 receptor A } \\
\text { (IL-17RA) to block the release of proinflammatory cytokines and chemokines } \\
\text { (Monin and Gaffen, 2018) }\end{array}$ \\
\hline $\begin{array}{l}\text { Interleukin } 23 \text { and related } \\
\text { cytokines inhibitors }\end{array}$ & Ustekinumab & $\begin{array}{l}\text { A human IgG } \kappa \text { monoclonal antibody that binds with high affinity to p40 subunit of } \\
\text { both IL-12 and IL-23 to reduce the expression of key cytokines, such as MCP-1, } \\
\text { TNF- } \alpha \text {, IP-10, and IL-8 (Benson et al., 2011) }\end{array}$ \\
\hline & Guselkumab & $\begin{array}{l}\text { A human IgG1 } 1 \lambda \text { monoclonal antibody that selectively blocks the IL-23 receptor and } \\
\text { reduces the serum levels of IL-17A, IL-17F, and IL-22 (Al-Salama and Scott, } \\
\text { 2018) }\end{array}$ \\
\hline & Tildrakizumab & $\begin{array}{l}\text { A human IgG1 } \kappa \text { monoclonal that binds to the p19 subunit of IL-23 and } \\
\text { consequently inhibits its interaction with the IL-23 receptor (Papp et al., 2015) }\end{array}$ \\
\hline & Risankizumab & $\begin{array}{l}\text { A human IgG1 monoclonal antibody against the p19 subunit of IL-23, resulting in } \\
\text { inhibition of its interaction with the IL-23 receptor (Haugh et al., 2018) }\end{array}$ \\
\hline
\end{tabular}

FDA, Food and Drug Administration. STAT5, Signal transducer and activator of transcription 5. Nrf2, Nuclear factor erythroid 2-related factor 2. MCP-1, Monocyte chemoattractant protein-1.

temporally heterogeneous (Gatenby and Gillies, 2004; Gatenby et al., 2006). However, recent studies reveal that GLUT1 upregulation is considered to be one of the most immediate events in the pathogenesis of psoriasis by promoting epidermal hyperproliferation, inflammation, and angiogenesis (Tao et al., 2008; Tochio et al., 2013; Hodeib et al., 2018). Moreover, it plays a significant role in the evolution of the disease as well as the development of associated comorbidities. It is now wellestablished that GLUT1 is strongly upregulated in psoriatic lesions, epidermal hyperplasia, and wound healing when compared with healthy skin (Tao et al., 2008; Tochio et al., 2013).

The results of the published data provide a strong rationale for the design and evaluation of glucose-conjugated antipsoriatic drugs to improve their pharmacokinetic and pharmacodynamic properties. Glycoconjugation of antipsoriatic drugs could generate a valuable treatment option for moderate to severe forms of psoriasis as well as comorbidities associated with the disease. In the case of classic comorbidities associated with psoriasis, such as psoriatic arthritis, evidence suggests that the uptake of radiolabeled glucose correlates with the degree of arthritis activity, which may allow the preferential accumulation of glucose-conjugated drugs in the inflamed regions (Mehta et al., 2011; Rose et al., 2014). Moreover, comorbidities related to treatment, such as nephrotoxicity (cyclosporine) and hepatotoxicity (methotrexate, leflunomide, and acitretin), may be limited because of the expected pharmacokinetic properties of these glucose conjugates.

\section{Perspectives in Antipsoriatic Drug Design}

Glycoconjugation generally offers improved water solubility and stability and, if the glycoside of choice is a GLUT substrate, the potential for selective targeting to pathologic cells. Glycoconjugation may facilitate the pharmacokinetics of cytotoxic exogenous molecules and ensure their facilitated transport through glucose receptors. Alternatively, compounds that have a sugar moiety may interact with the machinery for the intake and metabolism of glucose. Antimetabolites, which build on sugar structures, may, through competitive inhibition, disrupt the cellular metabolism to cause cell death (Harjes et al., 2012; Zhang et al., 2014).

Current evidence has shown that flavonoids, such as genistein, suppress psoriasis-related inflammation (Wang 
et al., 2019). Of the many possible structural modifications of isoflavones, those that form glycoconjugate derivatives deserve special attention. Previous results have shown that sugar derivatives of genistein were not only able to significantly facilitate the transport of polyphenol into the intracellular compartment but also to modify its mechanism of action and exert a dozen-times higher therapeutic effect than genistein alone (Rusin et al., 2011; Gogler-Pigłowska et al., 2012). These results provide a strong rationale to further develop and explore the biologic effect of glycoconjugates of active substances used in clinical practice. Thus, we propose methods for the synthesis of conjugates of clinically used antipsoriatic drugs, namely, cyclosporine, acitretin, and tofacitinib with glucose. It is expected that at least some of the undesirable effects of these drugs can be diminished by chemical modification because of preferential influx into the target cells. Moreover, it is assumed that the derivatives may exhibit increased cellular selectivity and a more significant therapeutic effect. The design of specific targeting ligands has been presented in several excellent review publications (Calvaresi and Hergenrother, 2013; Granchi et al., 2016), and our experience in the synthesis of glycoconjugates of biologically active compounds (Pastuch-Gawołek et al., 2016) is the starting point for planning complex glucose derivatives of selected drugs used in psoriasis therapy.

Glycoconjugate of Acitretin. Acitretin is a secondgeneration synthetic retinoid administered for moderate to severe psoriasis (Boehncke and Schön, 2015). Although acitretin is a widely used systemic agent for the treatment of psoriasis, the efficacy of the drug is notoriously variable. As reported, there was a dose-response trend, with the highest doses of acitretin (50-75 mg/day) proving more effective than lower doses (10-25 mg/day) (Goldfarb et al., 1988). Hyperlipidemia is an obvious side effect of acitretin, particularly hypertriglyceridemia (Orfanos et al., 1997). Further side effects include arthralgia, mucocutaneous dryness, and photosensitivity. These factors limit acitretin's clinical use, especially in patients with other risk factors for cardiovascular disease.

Retinoic acid analogs have emerged as important therapeutic agents for the treatment of various skin diseases (e.g., acne and psoriasis) and as potential cancer chemopreventive agents. Therefore, synthesis of acitretin derivatives with increased solubility as well as stability toward hydrolysis and oxidation was critical. Balakrishnan et al. (1997) reported that glucuronide conjugates of retinoids were active and exhibited improved hydrolytic stability. However, it was found that retinoid glucuronides do not bind to retinoid receptors, and their potential application in psoriasis was not reported. We propose the synthesis of D-glucose conjugates, potential ligands of GLUT1, that will undergo intracellular hydrolysis into acitretin and glucose. The strategy for the synthesis of the conjugate is shown in Fig. 2A. Amide formation is among the most widely studied and used transformation in synthetic chemistry. A vast range of coupling agents and carboxylactivating species, therefore, exist for undertaking such reactions (Valeur and Bradley, 2009; Koniev and Wagner, 2015). The known 2 -aminoethyl- or 3-aminopropyl- $\beta$-D-glucoside was treated with acitretinamide in the presence of carbon diimides as a coupling agent [e.g., $N$-(3-(dimethylamino)propyl)- $N^{\prime}$ ethylcarbodiimide, di-cyclohexylcarbodiimide] (Valeur and Bradley, 2009; Koniev and Wagner, 2015). The reaction is routinely conducted according to proposed procedures. Deprotection of the conjugate sugar portion is performed under standard conditions (basic conditions) by treatment with sodium methanolate. Moreover, taking into account the higher stability of $S$-glycosides in comparison with $O$-glycosides, the synthesis of acitretin glycoconjugate derivatives of 1-thioglycosides, containing an amino group in their aglycon, is shown in Fig. 2A (and follows a similar route as in the case of $O$-glycoside).

Glycoconjugate of Cyclosporin. Cyclosporin is a widely used immunosuppressant. Despite its everyday clinical use, it is associated with several side effects that include high blood pressure, headache, nephrotoxicity, increased hair growth, and vomiting as well as increased risk of infection, lymphoma, and liver problems (Tedesco and Haragsim, 2012). The increased blood pressure can cause cardiovascular events; it is thus recommended that the lowest effective dose for people requiring long-term treatment be used (Robert et al., 2010). Cyclosporin exhibits very poor solubility in water, and, as a consequence, suspension and emulsion forms of the medication have been developed for oral administration and injection. We expect that glycoconjugates may increase the bioavailability of the drug and optimize the formulation. The attachment of the sugar to result in a cyclosporine derivative glycopeptide is possible because of the functionalization of a double $\mathrm{C}=\mathrm{C}$ bond. The attractiveness of designed compounds stems from the belief that $C$-glycosides are better potential drug candidates because, compared with their $O$-glycoside parents, they are not only more stable to acid but also to glycosidases and thus will have better biologic halflives. We describe here a route to a C-glycoside analog of cyclosporin. Given its robustness and general ease of implementation, transition metal-catalyzed olefin metathesis has become an increasingly ubiquitous method for generating $\mathrm{C}-\mathrm{C}$ double bonds in a wide variety of fields, including organic synthesis, green chemistry, and biochemistry (Grubbs and Khosravi, 2015). In the method reported here, the critical step is an olefin cross-metathesis of allyl derivatives of D-glucose and peptide. Planned substrates are methyl 6-O-allyl-Dglucoside and allyl-D-glucopyranoside prepared according to known and effective procedures. The critical issue is to preserve the E-configuration of substituents on the cyclosporin derivatives. Recently, ruthenium-based olefin metathesis catalysts bearing dithiolate ligands have been employed to generate olefins with high selectivity, which made it possible to obtain almost exclusively the $\mathrm{E}$ isomer (>99\% $\mathrm{E})$ (Ahmed and Grubbs, 2017). These catalysts demonstrate significantly improved initiation, resulting in considerably increased activity of these catalysts in reactions of trans olefins and demonstrating higher yields at shorter reaction times while maintaining high stereoselectivity of products (>99\% E). The synthesis project is shown in Fig. 2C. In the planned reaction of olefin cross-metathesis leading to cyclosporine glycoconjugates, it was decided to use 6-O-allyl-D-glucoside, allyl- $\beta$-D-glucopyranoside, and $1 \mathrm{C}$-allyl- $\beta$-D-glucopyranoside as the sugar substrates.

Glycoconjugate of Tofacitinib. Janus activated kinases (JAKs) are a family of receptor-associated tyrosine kinases involved in several physiologic functions such as immune responses and are related to autoimmune and inflammatory diseases (Babon et al., 2014; Schwartz et al., 2016). Tofacitinib is a JAK inhibitor approved for the treatment of active psoriasis as well as rheumatoid arthritis. 
A<smiles>COc1c(C)c(C)c(/C=C/C(C)=C/C=C/C(C)=C/C(=O)O)c(C)c1N</smiles><smiles>[X]NC(=O)/C=C(C)/C=C/C=C(C)/C=C/c1cc(C)c(OC)cc1C</smiles>

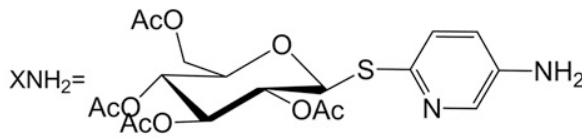

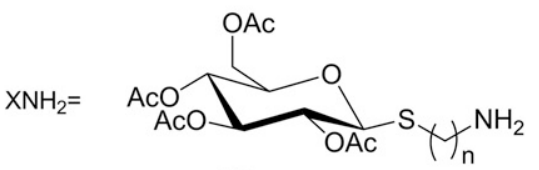

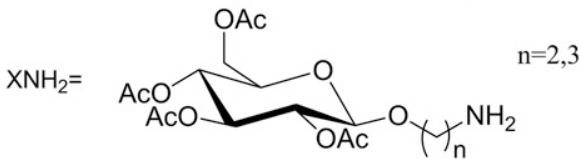

a) $\mathrm{XNH}_{2}$, carbodiimide coupling agent
B<smiles>C[C@H]1CC[Nb]C[C@@H]1N(C)c1nc(Cl)nc2[nH]ccc12</smiles>

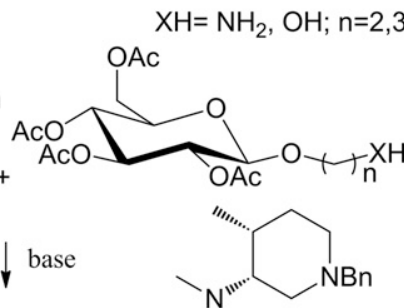<smiles>[X]c1nc(C)c2cc[nH]c2n1</smiles>

a)

C<smiles>CCOC1OCC(O)C(O)C(O)C1O</smiles><smiles>C=CCOC1COC(O)C(O)C(O)C1O</smiles>

a)<smiles>[X]c1nc(N(C)CCNC(=O)CCl)c2cc[nH]c2n1</smiles>

a) $\mathrm{DBU}, \mathrm{nBuOH}$<smiles>C1CC[Te]C1</smiles><smiles>CNC(=O)C(NC(=O)C(CC(C)C)N(C)C)C(C)C</smiles><smiles>CCNC(=O)C(C)CC(C)C</smiles><smiles>[PbH]</smiles><smiles>C=CN[C@@H](C)C(=C)N(C)C(C)C(=O)N(C)C1CC(C)CC1C(=C)N(C)C(C)C</smiles>

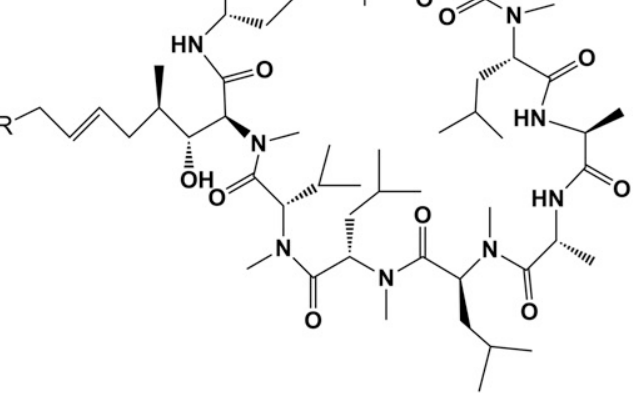

a) Grubbs catalyst

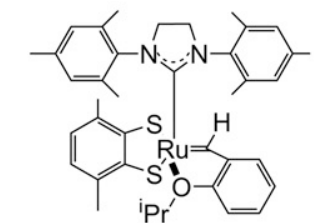

Fig. 2. Synthesis of glucose-conjugated antipsoriatic drugs. Synthesis of (A) acitretin glycoconjugate, (B) tofacitinib glycoconjugate, and (C) cyclosporin glycoconjugate.

A comprehensive analysis of the different synthetic methods used to prepare this active pharmaceutical ingredient was reported (Carvalho et al., 2019). The synthons (the building blocks) used in the synthesis of tofacitinib are 4-methyl 3- $N$ methyl-cis-piperidine and 2,4-dichloro-7H-pyrrolo[2,3-day] pyrimidine. The nucleophilic substitution of chlorine at the 
C-4 pyrimidine of the derivative with the amine group from the piperidine derivative according to a aromatic nucleophilic substitution mechanism is performed in the presence of a base such as $\mathrm{K}_{2} \mathrm{CO}_{3}$ or $\mathrm{Na}_{2} \mathrm{CO}_{3}$ (Renom-Carrasco et al., 2016).

In our proposal (Fig. 2B), the compound obtained in this reaction was a substrate for a second nucleophilic substitution reaction with a sugar derivative. Displacement of a chlorine atom in this compound by treatment with per-O-acetylated $\mathrm{D}$-glucose derivatives leads to the formation of the glycoconjugate. After removing the protecting benzyl group from the piperidine nitrogen atom by simple hydrogenolysis, this atom can be further functionalized. Price et al. (2009) described a single-step process for direct amidation of alkyl cyanoacetates using 1,8-diazabicyclo[5.4.0]undec-7-ene in n-butanol $(\mathrm{nBuOH})$. Under the proposed conditions, deacetylation of the sugar unit also takes place, and as a result, the desired drug is obtained.

\section{Assessment of Chemical Properties, the Bioactivity, and the Biodistribution of Glycoconjugates}

After synthesis and traditional liquid chromatography separation, the compound must be characterized to confirm the desired structure. It is advisable to perform the validation with both chromatographic and spectroscopic methods $(1 \mathrm{H}$ nuclear magnetic resonance, $13 \mathrm{C}$ nuclear magnetic resonance, high-resolution mass spectrometry) as well as to determine the optical purity using polarimetry. Compound stability, solubility, cellular uptake, biodistribution, and bioactivity need to be comprehensively evaluated to determine the potential clinical application of the conjugate. There are several well-established methods to evaluate the cellular uptake of glycoconjugates. Barnett et al. (1973) reported that GLUT-mediated drug entry could be measured using radiolabeled glucose, whereas Kim et al. (2012) suggest the use of 2-[N-(7-nitrobenz-2-oxa-1,3-diazol-4-yl) amino]-2-deoxy-d-glucose (2-NBDG), a fluorescent analog of d-glucose, as a marker for visualization of cellular uptake and biodistribution of a fluorescent deoxyglucose derivative. For confirmation as to whether glucose transporters are involved in the uptake of the glucose-conjugated compound, cytochalasin B and phloretin can be used as known inhibitors of GLUTs (Tomaszowski et al., 2017). After evaluation of the optimal dosage of glucose conjugates in vitro, it is advisable to perform in vivo studies on psoriasis mouse models to determine the pharmacokinetics, pharmacodynamics, and, in particular, the maximum tolerated dose as well as anti-inflammatory properties. Although there is a scarcity of data regarding the administration of glucose derivatives in psoriatic animal models, protocols for the evaluation of glucose conjugates in cancer therapy could be used as a reference (Liu et al., 2017). Moreover, drug serum stability, biodistribution in collected blood and urine, and visualization of the localization in the whole animal can be assessed using radiolabeled glucose (Stüben et al., 1996) or real-time whole-body near-infrared reflectance spectroscopy optical imaging (Zhou et al., 2009).

\section{Conclusions}

Notable advances in our understanding of psoriasis, courtesy of basic science observations, has opened new avenues for the treatment of skin diseases. Recent findings concerning the fundamental role of glucose metabolism and GLUT1 expression in the pathogenesis of psoriatic lesions brought to light approaches that have garnered much attention and proved successful in cancer treatment. Substantial advances in the emerging field of glycoconjugation highlight the rationale for the development of glucose-conjugated antipsoriatic drugs to increase their effectiveness, cellular selectivity, and tolerability. The presented approach that exploits the heightened glucose requirement of keratinocytes may revolutionize the management of psoriasis.

\section{Authorship Contributions}

Wrote or contributed to the writing of the manuscript: Makuch, Woźniak, Krawczyk, Pastuch-Gawołek, Szeja, Agrawal.

\section{References}

Acosta-Felquer ML, Rosa J, and Soriano ER (2016) An evidence-based review of certolizumab pegol in the treatment of active psoriatic arthritis: place in therapy, Open Access Rheumatol 8, pp 37-44.

Ahmed TS and Grubbs RH (2017) Fast-initiating, ruthenium-based catalysts for improved activity in highly E-selective cross metathesis. J Am Chem Soc 139: 1532-1537.

Al-Salama ZT and Scott LJ (2018) Guselkumab: a review in moderate to severe plaque psoriasis. Am J Clin Dermatol 19:907-918.

Armstrong EJ, Harskamp CT, and Armstrong AW (2013) Psoriasis and major adverse cardiovascular events: a systematic review and meta-analysis of observational studies. J Am Heart Assoc 2:e000062.

Ashley EA (2016) Towards precision medicine. Nat Rev Genet 17:507-522.

Babon JJ, Lucet IS, Murphy JM, Nicola NA, and Varghese LN (2014) The molecular regulation of Janus kinase (JAK) activation. Biochem $J$ 462:1-13.

Balak DM (2015) Fumaric acid esters in the management of psoriasis, Psoriasis (Auckl) 5, pp 9-23.

Balakrishnan V, Gilbert NE, Brueggemeier RW, and Curley RW (1997) N-linked glycoside/glucuronide conjugates of retinoids: acitretin. Bioorg Med Chem Lett 7: 3033-3038.

Barnett JE, Holman GD, and Munday KA (1973) Structural requirements for binding to the sugar-transport system of the human erythrocyte. Biochem $J$ 131:211-221.

Benson JM, Peritt D, Scallon BJ, Heavner GA, Shealy DJ, Giles-Komar JM, and Mascelli MA (2011) Discovery and mechanism of ustekinumab: a human monoclonal antibody targeting interleukin-12 and interleukin-23 for treatment of immune-mediated disorders. MAbs 3:535-545.

Boehncke W-H and Schön MP (2015) Psoriasis. Lancet 386:983-994

Bookstaver PB, Norris L, Rudisill C, DeWitt T, Aziz S, and Fant J (2008) Multiple toxic effects of low-dose methotrexate in a patient treated for psoriasis. Am J Heal Pharm 65:2117-2121.

Bronstein Y, Tummala S, and Rohren E (2011) F-18 FDG PET/CT for detection of malignant involvement of peripheral nerves: case series and literature review. Clin Nucl Med 36:96-100.

Calvaresi EC and Hergenrother PJ (2013) Glucose conjugation for the specific targeting and treatment of cancer. Chem Sci (Camb) 4:2319-2333.

Calvo MB, Figueroa A, Pulido EG, Campelo RG, and Aparicio LA (2010) Potential role of sugar transporters in cancer and their relationship with anticancer therapy. Int $J$ Endocrinol 2010:1-14.

Cantor JR and Sabatini DM (2012) Cancer cell metabolism: one hallmark, many faces. Cancer Discov 2:881-898.

Carvalho LCR, Lourenço A, Ferreira LM, and Branco PS (2019) Tofacitinib Synthesis - an Asymmetric challenge, Eur. J. Org. Chem. 2019, 4, 615- 624.

Castela E, Archier E, Devaux S, Gallini A, Aractingi S, Cribier B, Jullien D, Aubin F, Bachelez H, Joly P, et al. (2012) Topical corticosteroids in plaque psoriasis: a systematic review of risk of adrenal axis suppression and skin atrophy. $J$ Eur Acad Dermatol Venereol 26 (Suppl 3):47-51.

Chan ESL and Cronstein BN (2013) Mechanisms of action of methotrexate. Bull Hosp Jt Dis (2013) 71 (Suppl 1):S5-S8.

Conway R, Low C, Coughlan RJ, O’Donnell MJ, and Carey JJ (2015) Risk of liver injury among methotrexate users: a meta-analysis of randomised controlled trials. Semin Arthritis Rheum 45:156-162.

Crunkhorn S (2018) Autoimmune disease: targeting glucose transport in psoriasis. Nat Rev Drug Discov 17:394.

Davidson A and Diamond B (2001) Autoimmune diseases. N Engl J Med 345: 340-350.

Eaton WW, Rose NR, Kalaydjian A, Pedersen MG, and Mortensen PB (2007) Epidemiology of autoimmune diseases in Denmark. J Autoimmun 29:1-9.

Fala L (2016) Cosentyx (secukinumab): first IL-17a antagonist receives FDA approval for moderate-to-severe plaque psoriasis. Am Health Drug Benefits 9 (Spec Feature):60-63.

Feldman SR, Malakouti M, and Koo JY (2014) Social impact of the burden of psoriasis: effects on patients and practice. Dermatol Online $J \mathbf{2 0}$

Gatenby RA, Gawlinski ET, Gmitro AF, Kaylor B, and Gillies RJ (2006) Acidmediated tumor invasion: a multidisciplinary study. Cancer Res 66:5216-5223.

Gatenby RA and Gillies RJ (2004) Why do cancers have high aerobic glycolysis? Nat Rev Cancer 4:891-899.

Gerosa F, Baldani-Guerra B, Lyakh LA, Batoni G, Esin S, Winkler-Pickett RT Consolaro MR, De Marchi M, Giachino D, Robbiano A, et al. (2008) Differential 
regulation of interleukin 12 and interleukin 23 production in human dendritic cells. J Exp Med 205:1447-1461.

Goffe B and Cather JC (2003) Etanercept: an overview, J Am Acad Dermatol 49, pp S105-S111.

Gogler-Pigłowska A, Rusin A, Bochenek D, and Krawczyk Z (2012) Aneugenic effects of the genistein glycosidic derivative substituted at $\mathrm{C} 7$ with the unsaturated disaccharide. Cell Biol Toxicol 28:331-342.

Goldfarb MT, Ellis CN, Gupta AK, Tincoff T, Hamilton TA, and Voorhees JJ (1988) Acitretin improves psoriasis in a dose-dependent fashion. $J$ Am Acad Dermatol 18 $655-662$.

Granchi C, Fortunato S, and Minutolo F (2016) Anticancer agents interacting with membrane glucose transporters. MedChem Comm 7:1716-1729.

Grubbs RH and Khosravi E (2015) Handbook of Metathesis, Vol. 3: Polymer Synthesis, 2nd ed. Vol.3, Wiley-VCH, Weinheim, Germany.

Guo Y, Lu N, and Bai A (2013) Clinical use and mechanisms of infliximab treatment on inflammatory bowel disease: a recent update. Biomed Res Int 2013:581631.

Harjes U, Bensaad K, and Harris AL (2012) Endothelial cell metabolism and implications for cancer therapy. Br J Cancer 107:1207-1212.

Haugh IM, Preston AK, Kivelevitch DN, and Menter AM (2018) Risankizumab: an anti-IL-23 antibody for the treatment of psoriasis. Drug Des Devel Ther 12 $3879-3883$.

Hiebert P and Werner S (2018) Targeting metabolism to treat psoriasis. Nat Med 24: $537-539$

Hodeib AA-H, Neinaa YME, Zakaria SS, and Alshenawy HA-S (2018) Glucose transporter-1 (GLUT-1) expression in psoriasis: correlation with disease severity Int $J$ Dermatol 57:943-951.

Hodge JA, Kawabata TT, Krishnaswami S, Clark JD, Telliez JB, Dowty ME, Menon S, Lamba M, and Zwillich S (2016) The mechanism of action of tofacitinib - an oral Janus kinase inhibitor for the treatment of rheumatoid arthritis, Clin Exp Rheumatol 34, pp 318-328.

Jacobson DL, Gange SJ, Rose NR, and Graham NM (1997) Epidemiology and estimated population burden of selected autoimmune diseases in the United States. Clin Immunol Immunopathol 84:223-243.

Kim J and Krueger JG (2015) The immunopathogenesis of psoriasis. Dermatol Clin 33:13-23.

Kim WB, Jerome D, and Yeung J (2017) Diagnosis and management of psoriasis, Can Fam Physician 63, pp 278-285.

Kim WH, Lee J, Jung D-W, and Williams DR (2012) Visualizing sweetness: increasingly diverse applications for fluorescent-tagged glucose bioprobes and their recent structural modifications. Sensors (Basel) 12:5005-5027.

Kleyn EC, Morsman E, Griffin L, Wu JJ, Cm van de Kerkhof P, Gulliver W, van der Walt JM, and Iversen L (2019) Review of international psoriasis guidelines for the treatment of psoriasis: recommendations for topical corticosteroid treatments. $J$ Dermatolog Treat 30:311-319.

Koniev O and Wagner A (2015) Developments and recent advancements in the field of endogenous amino acid selective bond forming reactions for bioconjugation [published correction appears in Chem Soc Rev (2015) 44:5743]. Chem Soc Rev 44: $5495-5551$.

Lambert J, Ghislain PD, Lambert J, Cauwe B, and Van den Enden M (2017) Treatment patterns in moderate-to-severe plaque psoriasis: results from a Belgian cross-sectional study (DISCOVER). J Dermatolog Treat 28:394-400.

Langley RG, Krueger GG, and Griffiths CE (2005) Psoriasis: epidemiology, clinical features, and quality of life. Ann Rheum Dis 64 (Suppl 2):ii18-ii23; discussion ii24-5.

Lebwohl MG, Bachelez H, Barker J, Girolomoni G, Kavanaugh A, Langley RG, Paul CF, Puig L, Reich K, and van de Kerkhof PCM (2014) Patient perspectives in the management of psoriasis: results from the population-based Multinational Assessment of Psoriasis and Psoriatic Arthritis Survey. J Am Acad Dermatol 70:871-881-30.

Lebwohl MG, Kavanaugh A, Armstrong AW, and Van Voorhees AS (2016) US perspectives in the management of psoriasis and psoriatic arthritis: patient and physician results from the population-based multinational assessment of psoriasis and psoriatic arthritis (MAPP) survey. Am J Clin Dermatol 17:87-97.

Lerner A and Matthias T (2015a) Changes in intestinal tight junction permeability associated with industrial food additives explain the rising incidence of autoimmune disease. Autoimmun Rev 14:479-489.

Lerner A and Matthias T (2015b) Possible association between celiac disease and bacterial transglutaminase in food processing: a hypothesis. Nutr Rev 73:544-552. Levin EC, Gupta R, Brown G, Malakouti M, and Koo J (2014) Biologic fatigue in psoriasis. J Dermatolog Treat 25:78-82.

Liu D and Auguste DT (2015) Cancer targeted therapeutics: from molecules to drug delivery vehicles. J Control Release 219:632-643.

Liu R, Fu Z, Zhao M, Gao X, Li H, Mi Q, Liu P, Yang J, Yao Z, and Gao Q (2017) GLUT1-mediated selective tumor targeting with fluorine containing platinum(II) glycoconjugates. Oncotarget 8:39476-39496.

Lohi S, Mustalahti K, Kaukinen K, Laurila K, Collin P, Rissanen H, Lohi O, Bravi E Gasparin M, Reunanen A, et al. (2007) Increasing prevalence of coeliac disease over time. Aliment Pharmacol Ther 26:1217-1225.

Lowes MA, Bowcock AM, and Krueger JG (2007) Pathogenesis and therapy of psoriasis. Nature 445:866-873.

Lowes MA, Suárez-Fariñas M, and Krueger JG (2014) Immunology of psoriasis. Annu Rev Immunol 32:227-255.

Matsuda S and Koyasu S (2000) Mechanisms of action of cyclosporine.Immunopharmacology 47:119-125.

Maybury CM, Jabbar-Lopez ZK, Wong T, Dhillon AP, Barker JN, and Smith CH (2014) Methotrexate and liver fibrosis in people with psoriasis: a systematic review of observational studies. $\mathrm{Br} J$ Dermatol 171:17-29.

Mease PJ (2007) Adalimumab in the treatment of arthritis.Ther Clin Risk Manag 3 : $133-148$

Medina RA and Owen GI (2002) Glucose transporters: expression, regulation and cancer. Biol Res 35:9-26.
Mehta NN, Yu Y, Saboury B, Foroughi N, Krishnamoorthy P, Raper A, Baer A, Antigua J, Van Voorhees AS, Torigian DA, et al. (2011) Systemic and vascular inflammation in patients with moderate to severe psoriasis as measured by $[18 \mathrm{~F}]$ fluorodeoxyglucose positron emission tomography-computed tomography (FDGPET/CT): a pilot study. Arch Dermatol 147:1031-1039.

Monin L and Gaffen SL (2018) Interleukin 17 family cytokines: signaling mechanisms, biological activities, and therapeutic implications, Cold Spring Harb Perspect Biol 10.

Mrowietz U, Kragballe K, Reich K, Spuls P, Griffiths CEM, Nast A, Franke J, Antoniou C, Arenberger P, Balieva F, et al. (2011) Definition of treatment goals for moderate to severe psoriasis: a European consensus. Arch Dermatol Res 303:1-10.

O'Neill JL and Feldman SR (2010) Vitamine D analogue-based therapies for psoriasis. Drugs Today (Barc) 46:351-360.

Orfanos CE, Zouboulis CC, Almond-Roesler B, and Geilen CC (1997) Current use and future potential role of retinoids in dermatology. Drugs 53:358-388.

Papp K, Thaçi D, Reich K, Riedl E, Langley RG, Krueger JG, Gottlieb AB, Nakagawa H, Bowman EP, Mehta A, et al. (2015) Tildrakizumab (MK-3222), an anti-interleukin-23p19 monoclonal antibody, improves psoriasis in a phase IIb randomized placebo-controlled trial [published correction appears in Br J Dermatol (2016) 174:1426] Br J Dermatol 173:930-939.

Pastuch-Gawołek G, Malarz K, Mrozek-Wilczkiewicz A, Musioł M, Serda M, Czaplinska B, and Musiol R (2016) Small molecule glycoconjugates with anticancer activity. Eur J Med Chem 112:130-144.

Patra M, Johnstone TC, Suntharalingam K, and Lippard SJ (2016) A potent glucoseplatinum conjugate exploits glucose transporters and preferentially accumulates in cancer cells. Angew Chem Int Ed Engl 55:2550-2554.

Pearce HP and Wilson BB (1996) Erosion of psoriatic plaques: an early sign of methotrexate toxicity. J Am Acad Dermatol 35:835-838.

Pohl J, Bertram B, Hilgard P, Nowrousian MR, Stüben J, and Wiessler M (1995) D19575--a sugar-linked isophosphoramide mustard derivative exploiting transmembrane glucose transport. Cancer Chemother Pharmacol 35:364-370.

Price KE, Larrivée-Aboussafy C, Lillie BM, McLaughlin RW, Mustakis J, Hettenbach KW, Hawkins JM, and Vaidyanathan R (2009) Mild and efficient DBU-catalyzed amidation of cyanoacetates. Org Lett 11:2003-2006.

Rendon A and Schäkel K (2019) Psoriasis pathogenesis and treatment. Int J Mol Sci 20

Renom-Carrasco M, Gajewski P, Pignataro L, de Vries JG, Piarulli U, Gennari C, and Lefort L (2016) Asymmetric hydrogenation of 3-substituted pyridinium salts. Chemistry 22:9528-9532.

Robert N, Wong GW, and Wright JM (2010) Effect of cyclosporine on blood pressure. Cochrane Database Syst Rev (1):CD007893.

Roenigk HH Jr., Auerbach R, Maibach HI, and Weinstein GD (1988) Methotrexate in psoriasis: revised guidelines. J Am Acad Dermatol 19:145-156.

Rønholt K and Iversen L (2017) Old and new biological therapies for psoriasis. Int J Mol Sci 18

Rose S, Dave J, Millo C, Naik HB, Siegel EL, and Mehta NN (2014) Psoriatic arthritis and sacroiliitis are associated with increased vascular inflammation by 18-fluorodeoxyglucose positron emission tomography computed tomography: baseline report from the Psoriasis Atherosclerosis and Cardiometabolic Disease Initiative. Arthritis Res Ther 16:R161.

Rusin A, Zawisza-Puchałka J, Kujawa K, Gogler-Pigłowska A, Wietrzyk J, Świtalska M, Głowala-Kosińska M, Gruca A, Szeja W, Krawczyk Z, et al. (2011) Synthetic conjugates of genistein affecting proliferation and mitosis of cancer cells. Bioorg Med Chem 19:295-305.

Schafer P (2012) Apremilast mechanism of action and application to psoriasis and psoriatic arthritis, Biochem Pharmacol 83, pp 1583-1590.

Schwartz DM, Bonelli M, Gadina M, and O'Shea JJ (2016) Type I/II cytokines, JAKs, and new strategies for treating autoimmune diseases. Nat Rev Rheumatol 12: 25-36.

Singh RK, Lee KM, Jose MV, Nakamura M, Ucmak D, Farahnik B, Abrouk M, Zhu TH, Bhutani T, and Liao W (2016) The patient's guide to psoriasis treatment. Part 1: UVB phototherapy, Dermatol Ther (Heidelb) 6, pp 307-313.

Srinivasarao M, Galliford CV, and Low PS (2015) Principles in the design of ligandtargeted cancer therapeutics and imaging agents. Nat Rev Drug Discov 14 203-219.

Srinivasarao M and Low PS (2017) Ligand-targeted drug delivery. Chem Rev 117: 12133-12164.

Stüben J, Port R, Bertram B, Bollow U, Hull WE, Schaper M, Pohl J, and Wiessler M (1996) Pharmacokinetics and whole-body distribution of the new chemotherapeutic agent $\beta$-D-glucosylisophosphoramide mustard and its effects on the incorporation of [methyl-3H]-thymidine in various tissues of the rat. Cancer Chemother Pharmacol 38:355-365.

Szablewski L (2013) Expression of glucose transporters in cancers. Biochim Biophys Acta 1835:164-169.

Tao J, Yang J, Wang L, Li Y, Liu YQ, Dong J, Li L, Wen X, Shen GX, and Tu YT (2008) Expression of GLUT-1 in psoriasis and the relationship between GLUT-1 upregulation induced by hypoxia and proliferation of keratinocyte growth J Dermatol Sci 51:203-207.

Tedesco D and Haragsim L (2012) Cyclosporine: a review. J Transplant 2012:230386.

Tippmann F, Hundt J, Schneider A, Endres K, and Fahrenholz F (2009) Upregulation of the alpha-secretase $\mathrm{ADAM} 10$ by retinoic acid receptors and acitretin FASEB J 23:1643-1654.

Tochio T, Tanaka H, and Nakata S (2013) Glucose transporter member 1 is involved in UVB-induced epidermal hyperplasia by enhancing proliferation in epidermal keratinocytes. Int J Dermatol 52:300-308.

Tomaszowski K-H, Hellmann N, Ponath V, Takatsu H, Shin H-W, and Kaina B (2017) Uptake of glucose-conjugated MGMT inhibitors in cancer cells: role of flippases and type IV P-type ATPases. Sci Rep 7:13925.

Valeur E and Bradley M (2009) Amide bond formation: beyond the myth of coupling reagents. Chem Soc Rev 38:606-631. 
Vander Heiden MG (2011) Targeting cancer metabolism: a therapeutic window opens. Nat Rev Drug Discov 10:671-684.

Wang A, Wei J, Lu C, Chen H, Zhong X, Lu Y, Li L, Huang H, Dai Z, and Han L (2019) Genistein suppresses psoriasis-related inflammation through a STAT3-NFкB-dependent mechanism in keratinocytes. Int Immunopharmacol 69:270-278.

Warburg O (1956) On the origin of cancer cells. Science 123:309-314

Zhang D, Li J, Wang F, Hu J, Wang S, and Sun Y (2014) 2-Deoxy-D-glucose targeting of glucose metabolism in cancer cells as a potential therapy. Cancer Lett 355:176-183. Zhang Z, Zi Z, Lee EE, Zhao J, Contreras DC, South AP, Abel ED, Chong BF, Vandergriff T, Hosler GA, et al. (2018) Differential glucose requirement in skin homeostasis and injury identifies a therapeutic target for psoriasis. Nat Med 24: 617-627.

Zhou H, Luby-Phelps K, Mickey BE, Habib AA, Mason RP, and Zhao D (2009) Dynamic near-infrared optical imaging of 2-deoxyglucose uptake by intracranial glioma of athymic mice. PLoS One 4:e8051.

Address correspondence to: Siddarth Agrawal, K. Marcinkowskiego 1, 50368 Wrocław, Poland. E-mail: siddarth@agrawal.pl 